\title{
CUBA: LOS ENTORNOS CAMBIANTES DE LA PARTICIACIÓN
}

\author{
Haroldo Dilla Alfonso*
}

Fecha de recepción: abril de 1999

Fecha de aceptación y versión final: septiembre de 1999

Resumen: La participación popular ha sido una permanente invocación del discurso político revolucionario cubano, particularmente en las instancias comunitarias. Este ensayo trata de analizar la evolución de los diseños, instituciones y realidades participativas a partir de su relación con las situaciones políticas y los modelos de reproducción económicos. Por su relevancia, se presta especial atención al sistema municipal cubano. Este fue creado en 1976 y ha experimentado diversas modificaciones, las más importantes de las cuales tuvieron lugar en 1992.

Los cambios económicos y sociales que han tenido lugar en Cuba en los últimos diez años imponen a la participación nuevos retos, entre ellos la necesidad de una concepción más autónoma y pluralista del accionar popular en la esfera pública, lo que de alguna manera ya se expresa en algunos esfuerzos oficiales por adecuar los patrones de participación existentes (esencialmente una participación paternalista-clientelista) y en la emergencia de movimientos comunitarios que intentan controlar y transformar las vidas cotidianas en los vecindarios.

Palabras clave: Participación popular, discurso político, accionar popular, movimientos sociales comunitarios.

Abstract: Popular participation has been a permanent slogan in the political discourse of revolutionary Cuba, particularly at the community level. This article deals with the design and evolution of institutions and participatory realities starting with its relation with the political situation and economic models of reproduction. Special attention is given to the municipal system created in 1976 and modified several times from which the most important modification was the one in 1992.

The social and economic changes of Cuba during the last ten years have posed new challenges to participation such as the need for a more autonomous and pluralistic conception of "popular praxis" in the public sphere. This is present in the official efforts to adequate existing participatory norms (particularly the paternalistic-clientelistic participation) and it is also present in the emergency of community or popular movements that attempt to control and to transform the dayly life in their neighborhood.

Key words: Popular participation, political discourse, popular praxis, community social movements.

\section{INTRODUCCIÓN}

La historia revolucionaria cubana ha estado marcada por un discurso invocativo de una sociedad democrática radical cuyos principios fundacionales -la igualdad y la participación- resultaban congruentes con la meta más general de superación del orden capitalista y de su expresión política más sofisticada: la democracia liberal. Cuarenta años después son perfectamente conocidos los logros y los déficits de este proyecto emancipatorio sin precedentes en América Latina. Por un lado, fue una voluntad revolucionaria que produjo una sociedad de prosperidad discreta, pero equitativa, que consagró como un punto no negociable de la agenda política la realización de los derechos sociales y económicos de las mayorías populares, e impulsó un intenso proceso de movilidad social ascendente. Por el otro lado, se hizo al costo de limitar importantes derechos civiles y políticos, así como el ejercicio de prácticas democráticas indispensables. De hecho, el sistema político quedó estructurado a partir de una alta concentración de la autoridad en manos de un liderazgo revolucionario que no conoció más límite interno decisorio que su propio sentido común, pero que al mismo tiempo supo asumir con notable habilidad los atributos de la autoridad y de la potestad de cara a una sociedad poco diferenciada y con un bajo nivel de reflexividad. Como se tratará de explicar más adelante, esta serie de factores han ido incidiendo en los esquemas y las calidades de los procesos participativos en los municipios y en las sociedades locales en general.

Durante el período 1959-1976 la participación popular tuvo un carácter consultivo y de apoyo, mediada por una relación muy activa de las masas populares con un lideraz-

* Historiador y sociólogo, ha publicado más de una decena de libros y numerosos artículos en revistas especializadas. Durante 16 años fue director de investigaciones latinoamericanas del Centro de Estudios sobre América. En la actualidad es coordinador de proyectos de la Facultad Latinoamericana de Ciencias Sociales en Santo Domingo y miembro de la Unión Nacional de Escritores y Artistas de Cuba. $\square$ local@ip.etecsa.cu 
go dinámico. La literatura sociológica de la época' da cuenta de una intensa movilización de masas y de la organización entusiasta de la población en diversas organizaciones barriales o sectoriales (Comités de Defensa de la Revolución, Federación de Mujeres Cubanas, etc.), así como de un fuerte involucramiento de la población en tareas relacionadas con la producción, la defensa nacional y el apoyo simbólico a las medidas revolucionarias en función del desarrollo, la construcción socialista y el antiimperialismo. No existían, sin embargo, estructuras formales estables que canalizaran la participación, a excepción de las mencionadas organizaciones sociales y de masas. No había un sistema municipal. En los primeros años de la revolución fueron creadas algunas estructuras de coordinación a nivel local, y sólo en 1965 se intentó la creación de un sistema de administraciones locales que intentó sin éxito generar sus propios espacios participativos hasta su total burocratización a principios de los 70 (García Cárdenas, 1989).

El actual esquema municipal cubano fue establecido en 1976, en el marco de un proceso de reestructuración de todo el sistema político administrativo y en cierta medida también de las relaciones políticas, externas e internas. Este proceso, denominado "proceso de institucionalización", tuvo como pivote principal la culminación de la inserción económica de Cuba al bloque este-europeo, con consecuencias previsibles en cuanto al acceso a recursos externos relativamente abundantes, la instauración de un modelo de crecimiento extensivo coordinado por una planificación severamente centralizada y a la adopción de otros "usos y costumbres" propios del sistema soviético. Fue una suerte de sovietización afortunadamente parcial, en la medida en que la clase política revolucionaria tuvo la virtud de proteger diversos espacios de autoctonía y en que la cultura popular no fue capaz de digerir los rasgos más letánicos de los regímenes socialistas burocráticos afincados tras el Muro de Berlín.

En realidad los municipios establecidos en 1976 (169 en total, el mayor con medio millón de habitantes y el menor con 7 mil, más de la mitad del total con poblaciones oscilantes entre 25 y $100 \mathrm{mil}$ ) eran órganos político administrativos con funciones delegadas desde el poder central, sin una clara delimitación de atribuciones, y por consiguiente sujetos a frecuentes recentralizaciones. Así, los municipios pasaron a ser depositarios de la administración de los servicios de salud y educación, del comercio estatal minorista, y de otras funciones que, como limpieza de calles o mantenimiento de áreas verdes, corresponden a cualquier municipio. De igual manera fueron investidos de un discreto papel de coordinación entre los actores económicos de los territorios (grandes empresas o unidades de servicios) y de funciones fiscales y estadísticas. Pero sus niveles de autonomía para conformar o ejecutar sus presupuestos y sus planes de desarrollo eran severamente constreñidos. Las capacidades municipales para movilizar recursos locales eran muy limitadas por una rígida normativa centralista que incluso les impedía un real control sobre el bien más preciado de cualquier municipio: el suelo.

Con lo anterior se dista de afirmar que fueran entes irrelevantes. Cualquier localidad cubana puede mostrar la eficacia de la actividad municipal, sea desarrollando proyectos propios o como vectores de planes nacionales. Lo que se desea apuntar es que el municipio cubano resultaba, más que una expresión política de la sociedad local, un espacio localizado del gobierno central, y su plan de desarrollo no rebasaba el status de una parcela del plan nacional con algunos aderezos locales. El sistema de gobierno constituido se denominaba "Poder Popular". Un chiste de la época afirmaba que era mucho más "popular" que "poder".

\section{LA PARTICIPACIÓN INSTITUCIONALIZADA $(1976-1990)^{2}$}

El chiste no era infundado. Curiosamente, el diseño municipal establecido en 1976 prestaba una mayor atención a los problemas de la democracia y su normatividad de manera que los municipios pasaron a ser un espacio de una normatividad democrático-participativa envidiable. Pero al mismo tiempo, con déficits provenientes del propio diseño o de desviaciones motivadas por el entorno político centralista.

El diseño participativo se apoyaba en la idea de que todo el poder residía en el Pueblo, concepto éste que era entendido como una masa homogénea articulada por el propio programa revolucionario: del Pueblo dimanaban las instituciones, cuya jerarquía formal se organizaba en cada instancia (municipio, provincia, nación) según su relación más estrecha con el voto. Así, en los municipios, las máximas autoridades estatales eran las asambleas municipales, compuestas por delegados nominados y elegidos cada dos años y medio por voto directo, secreto y libre en las circunscripciones. Estas asambleas eran dotadas con atribuciones varias tales como la elección y revocación de los comités ejecutivos y los alcaldes, la designación de todos los funcionarios con rango dirigente, la aprobación del presupuesto y de los planes de desarrollo, y la supervisión, mediante comisiones especializadas, de las funciones gubernamentales.

La relación de la población con sus delegados (unos 13 mil en todo el país) no cesaba en la acción electoral, sino que se extendía a diversos tipos de contactos personales o a reuniones vecinales - denominadas "reuniones de rendición de cuenta"- donde los electores podían expresar demandas, quejas o sugerencias sobre el ejercicio del gobierno local, lo que se veía fortalecido por la retención por la población del derecho a la revocación de sus delegados: al mismo tiempo, producía acuerdos de involucramiento de la gente en la construcción de obras sociales y en reparaciones de viviendas, por ejemplo.

1. En cuanto hecho revolucionario, Cuba despertó el interés de lo más selecto del pensamiento social de la época. Maurice Zeitling, Paul Sweezy, Leo Huberman, Jean Paul Sartre, Oscar Lewis, entre otros, dejaron testimonios del proceso inicial de cambios. Habría que lamentar dos cosas. En primer lugar, la manera tan poco estimulante como estas obras cubanológicas han sido olvidadas e incluso estigmatizadas en Cuba. En segundo, el retraso de la mayor parte de la producción cubanológica posterior, que no ha podido despegarse de una percepción altamente ideologizada del proceso cubano.

2. En este acápite sigo de cerca los resultados obtenidos en una investigación empírica sobre el sistema municipal, que dirigí entre 1988 y 1991, lamentablemente la única realizada y publicada en Cuba hasta el momento. Ver DILLA, et. al. (1993). 
Un esquema de esta naturaleza tenía ventajas innegables. Partiendo de un Estado con recursos relativamente abundantes y una alta vocación social, las demandas de la población eran objeto de una atención predilecta, sea para tomar acciones correctivas o para dar explicaciones más o menos convincentes acerca de las dificultades y sus vías futuras de solución. El cúmulo de demandas era registrado a todos los niveles y actuaba como un alimentador informativo de un sistema político altamente concentrado, lo que permitía a los dirigentes políticos poner rumbo a sus decisiones en función de las necesidades expresadas, y en esa misma dirección, retroalimentar la legitimidad del régimen incrementando sus niveles de rendimiento. Por otra parte, la población involucrada en estas actividades tenía ante si una oportunidad de participación que contribuyó a modelar una cultura política permeada por la idea de que la arena pública también pertenecía a la gente común mientras que cientos de miles de personas se entrenaron en funciones de liderazgo comunitario ${ }^{3}$.

Sin embargo, una evaluación cualitativa de estos procesos participativos pudiera conducirnos a resultados menos alentadores. En primer lugar, la participación comunitaria desarrollada en este contexto, no importa cuan funcional fuese a los fines de legitimación del sistema o a los propósitos sociales altruistas que animaban a sus diseñadores, padecía de una carencia crónica de autonomía. Los ciudadanos y las ciudadanas eran convocados a participar en procesos diseñados desde arriba y de manera uniforme para todo el país; efectivamente, podían incidir en los procesos de toma de decisiones, pero sólo de manera parcial, en sus fases iniciales y terminales. Así, las personas podían participar en la fase de agregación de demandas, y eventualmente podían involucrarse en la ejecución de las soluciones dadas a estas demandas, pero las fases de procesamiento de las demandas hasta devenir opciones de soluciones eran cotos exclusivos de grupos técnicos o burocráticos, locales o nacionales. En la medida en que las asambleas vecinales dejaban un espacio para evaluar los resultados de las labores del gobierno municipal y del propio delegado, puede argumentarse que también existía un cierto espacio para medir los resultados, pero en general esta posibilidad estaba limitada por la insuficiente información que se brindaba a los ciudadanos y ciudadanas. Las personas comunes quedaban así limitadas a un papel de productores de demandas y consumidores de decisiones adoptadas en otros lugares.

En segundo lugar, se trataba de una participación marcada por la atomización de los participantes en detrimento de las acciones o enfoques colectivos de las demandas. Así, las personas producían demandas a título individual y casi nunca con algún precedente de concertación colectiva que rebasara el ámbito más íntimo de la familia. Ciertamente el elemento colectivo se reforzaba en las acciones de ejecución, pero no implicaba una concertación rebasante de los objetivos concretos de la acción. Este resultado puede parecer contradictorio con una matriz social que enfatiza el elemento colectivo sobre el individual, pero no debe perderse de vista que al paso de los años, el discurso oficial tendió a diluir lo colectivo en la dimensión abstracta de "pueblo" (como substanciación de la comunidad nacional) y cuya representación era asumida por la "vanguardia política". En términos prácticos el resultado había sido la conversión de las otrora vigorosas organizaciones sociales y de masas en "correas de transmisión" y sus empobrecimientos en cuanto asociaciones representativas de los diferentes sectores sociales engarzados en el proyecto revolucionario.

Una tercera característica de esta participación era el parroquialismo de sus temas. Un análisis de los temas tratados en estas reuniones durante un período de un año, reveló que sus agendas de discusión estaban abrumadoramente saturadas de temas que no rebasaban los aspectos más existenciales de la vida cotidiana. Aquí incidía la fuerte centralización, ante la cual cualquier tema complejo hubiera caído inevitablemente en el vacío del silencio burocrático (Dilla, 1996).

La debilidad de los procesos de participación influía negativamente en la selección de los liderazgos locales y su confluencia en una instancia representativa, la asamblea municipal, que como decíamos era proclamada como la máxima autoridad estatal en el territorio. Los procesos de nominación de candidatos y elecciones de delegados, esencialmente libres y democráticos, estaban guiados por la selección de personas honestas, con probada vocación social y plena disposición para tramitar las demandas de los electores, pero menos inclinadas a la acción de gobernar. Las asambleas municipales quedaban así compuestas por delegados de una virtuosidad encomiable, pero pocas capacidades para discutir sobre temas como los presupuestos locales, los planes de desarrollo o simplemente para apreciar el valor de la autogestión.

En realidad, las formas de participación y representación antes descriptas hablan de la consolidación de una relación clientelista-paternalista entre la sociedad y el Estado cuya efectividad a largo plazo dependía del mantenimiento de una asimetría marcada entre un estado sumamente poderoso y una sociedad en proceso de recomposición. En un primer plano, se trataba de un Estado que detentaba altas capacidades extractivas y distributivas de recursos relativamente abundantes (ante todo materiales, pero también recursos políticos e ideológicos) que podían ser movilizados en función de las demandas en plazos de tiempo aceptables. Y el Estado cubano no sólo disfrutó de esas capacidades, sino que lo hizo con una excepcional autonomía respecto al cuerpo social y en condiciones cuasi-monopólicas. Su contraparte, la sociedad cubana, era un cuerpo en proceso de recomposición, afectado inicialmente por una nivelación radical y posteriormente por una intensa movilidad social que no daría sus frutos sino hasta la segunda mitad de los 80 . La sociedad civil ${ }^{+}$era una franja difusa de

3. La población hizo un uso extendido de estos mecanismos. Según las estadísticas emitidas por la Asamblea Nacional del Poder Popular entre octubre de 1988 y abril de 1989, se habían formulado en los municipios un total de 79.377 demandas, de las cuales el $79 \%$ habían sido realizadas en las asambleas vecinales. En un conteo empírico realizado en 1990 en varios municipios, encontramos que entre un $77 \%$ y un $53 \%$ de todas las demandas tenían lugar en las asambleas, con una frecuencia más baja en la capital, donde sus habitantes usaban más regularmente el recurso de la queja directa a las instancias nacionales.

4. Aquí entiendo por sociedad civil a todo el tejido social formado por asociaciones, canales de comunicación y relaciones regulares, hete- 
organizaciones altamente burocratizadas o de una miríada de pequeñas organizaciones fraternales, culturales, etc., con poca o ninguna influencia pública.

Esta situación comenzó a cambiar desde fines de los 80 . La desintegración del bloque este-europeo, el recrudecimiento del bloqueo americano y la dificultad para acceder a los mercados internacionales de capitales, significaron un golpe brutal a la economía nacional y a las capacidades estatales de regulación. Se inició una reforma económica que ha ido transfiriendo al mercado espacios importantes de regulación y asignación de recursos, aun cuando reservando al Estado el rol decisivo. El discurso oficial cubano, y sus tributarios desde la academia, dieron cuenta de esta situación denunciando el "paternalismo" estatal, pero obviando su contraparte inseparable: el clientelismo. Omitiendo, por consiguiente, que no estaban en presencia de un simple estilo de administración, sino de una relación de "bienes intercambiables" en que la sociedad recibía seguridad socioeconómica y posibilidades de ascenso a cambio de una lealtad sin fisuras que el Estado requería constantemente, en ocasiones en relación con políticas estrictamente puntuales.

Del otro lado de la balanza, la sociedad cubana a fines de los 80 era muy diferente a la que asistió llena de expectativas a la inauguración del Poder Popular unos lustros atrás. La intensa movilidad social provocada por los programas de educación y salud, por el pleno empleo, y por la propia experiencia acumulada en décadas de participación y enrolamiento en acciones públicas, había creado un sujeto social altamente capacitado y diversificado. De aquí en adelante, el concepto de pueblo solo podía ser entendido en relación con una diversidad social y de autoreconocimiento de identidades que reclamaba espacios diferentes de reproducción de la vida cotidiana y de interacción pública.

\section{LA COMUNIDAD REVALIDADA}

La crisis abrió el escenario a dos nuevos actores en los procesos de asignación de recursos y valores que hasta el momento había controlado el Estado en condiciones casi monopólicas: el mercado y la comunidad. Por supuesto que entraron por dos puertas diferentes. El mercado hizo su aparición de la mano del proceso de liberalización y ajuste de la economía, y junto con sus virtudes también comenzó a acarrear sus siempre lamentables consecuencias en cuanto a un aumento de la desigualdad social expresada en el surgimiento de una (aún incipiente) élite tecnocrática empresarial y de grupos sociales especialmente desfavorecidos a pesar de las prevenciones adoptadas por el Estado para evitar la pobreza extremas.

La comunidad, en cambio, apareció como resultado combinado de al menos tres factores. En primer lugar, la crisis económica impidió al Estado ejercer la regulación social y la provisión de servicios con la misma eficacia que en la década precedente. En la misma medida en que son servicios de los que el mercado no se ocupa regularmente -menos aún en Cuba donde los mercados son todavía muy fragmentados-aquí se abrió una tierra de nadie que fue llenada en muchos lugares por la acción directa de los pobladores.
Esta "invasión" -y es el segundo factor en juego- fue llevada a cabo por una población que había gozado del intenso proceso de movilidad social ascendente en los años anteriores y que portaba una rica experiencia en asuntos de participación, lo que en buena medida explica los avances y las "sofisticaciones" sorprendentes de los movimientos comunitarios cubanos. Por último, y es a lo que quiero referirme con más detalles, desde fines de los 80 estaba teniendo lugar un interesante proceso de apertura de espacios institucionales favorables a estas organizaciones desde el propio Estado y sus agencias técnicas. De esta manera, el Estado cubano ha devenido -probablemente con toda la contrariedad de sus sectores burocráticos más conservadores- en un constructor de sociedad civil (Dilla, Fernández y Castro, 1997).

Si se examinan primero los propios cambios institucionales introducidos por el Estado, los balances realizados a fines de los 80 indicaban claramente que las acciones participativas municipales $-\mathrm{y}$ muy especialmente las mencionadas reuniones de rendición de cuenta- habían caído en una cadencia rutinaria y sus asistentes estaban más interesados en cumplir con un deber cívico o político que en participar: Por otra parte, el Estado no podía ya digerir los centenares de miles de demandas de la población que se originaban en cada proceso nacional de rendición de cuenta. De aquí que estas reuniones fueran reinterpretadas, y en su nueva versión aparecieran propuestas más dinámicas que enfatizaban la búsqueda de soluciones colectivas desde la comunidad (palabra esta que empezó a usarse con notable frecuencia en los documentos alegóricos) y la introducción de algunos elementos de debate sobre los temas nacionales y locales ${ }^{6}$

Los balances realizados sobre las reuniones de rendición de cuentas indican el interés oficial por cambiar el propio sentido del término participación. "No podemos buscar una mayor participación sólo en los asuntos clásicos de solicitudes -afirma el documento antes citado- (sino en la) ... discusión (sobre) los problemas del barrio, los problemas de la sociedad y lo relacionado con la economía del lugar." De aquí el énfasis en la generación de "compromisos" de la comunidad para dar solución a los problemas confrontados. Estos compromisos se habían incrementado considerable-

rogéneas en sus composiciones sociales y metas y que coexisten en escenarios de conflictos, negociaciones y acuerdos. Por definición, es diferente tanto del Estado como del mercado, pero no necesariamente opuesta a éstos. La sociedad civil es vista así como una interacción comunicativa y de acción de grupos que conforman nuevas relaciones de poder o afectan las existentes, sea consolidándolas o erosionándolas. Al mismo tiempo, cada sociedad civil es una construcción histórico-cultural, y por consiguiente modelada a partir de las características de cada comunidad nacional o local (Oxhorn, 1995).

5. Este proceso de diferenciación social es una de las claves para entender la remodelación de la sociedad cubana y las peculiaridades de la sociedad civil emergente. Analizo este proceso con más detalles en (DILLA, 1999a).

6. En realidad esto fue un proceso paulatino. Durante la investigación sobre municipios de 1988-1991 era perceptible este cambio. En los inicios de la investigación, los delegados se sentían halagados de haber recibido muchas demandas, pues consideraban que ello significaba un reconocimiento de los electores a sus capacidades "para resolver problemas". Al final de la investigación los delegados iban a las reuniones con sus electores dispuestos a abortar cuanta demanda fuese posible, y el éxito del delegado se medía por su habilidad para hacerlo con explicaciones y tacto político. Sencillamente la investigación había comenzado en una época y terminado en otra. 
mente a la altura de 1997, llegando a englobar el 40\% de las demandas producidas (un total de 120 mil en más de 62 mil reuniones), pero aquí nuevamente resalta un déficit: los compromisos estaban concentrados básicamente en los municipios y provincias más tradicionales, mientras que sus frecuencias eran muy bajas en los municipios de la capital y de las provincias más urbanizadas (ANPP, 1997).

Pero quizás la innovación institucional más novedosa fue la creación de los consejos populares como unidades sub-municipales, y que de alguna manera convirtió al sistema municipal en lo que Bowman y Hapton (1993) han denominado un sistema de "filas múltiples". Los consejos fueron creados en un período comprendido entre 1989 y 1991 , y se componen de los delegados de circunscripciones de una zona específica (en ocasiones, barrios con identidad cultural e histórica). Al frente de cada consejo se encuentra un presidente, quien debe ser delegado de circunscripción y que resulta elegido por los delegados de circunscripciones comprendidas en el consejo. Además, al consejo asisten representantes de las organizaciones sociales y de masas y de empresas y unidades de servicios radicadas en el territorio del consejo. Hasta el momento no existe un documento normativo del funcionamiento de los consejos, pero las directivas iniciales enfatizaban un papel de control sobre los recursos locales y la lucha contra la corrupción y la especulación que desatan todos los períodos críticos como el que comenzó a experimentarse en 1990. Legalmente los consejos no tienen prerrogativas decisorias en lo relacionado al uso del presupuesto ni a la asignación de recursos. De hecho, en la medida en que se relacionan con empresas nacionales y otras entidades económicas, logran movilizar recursos en función de obras menores en las comunidades, tales como reparaciones de escuelas, instalaciones de salud pública y viales. Aunque todas estas funciones estaban acompañadas por una convocatoria a una mayor participación, nada indica en la mayoría de los consejos una motivación por una participación cualitativamente superior ya que muchos consejos quedaron limitados a estas funciones de coordinación sin más aspiraciones. Pero los consejos populares contenían en sí la contradicción de todo Estado que pretende penetrar los menores intersticios de la vida cotidiana. Cuando por razones diversas -capacitación de los líderes del consejo, demandas de los pobladores, etc.- el consejo comienza a desbordar el plano normativo más estricto, sus acciones tienden a organizarse a partir de una lógica diferente de la del Estado, y devienen espacios incipientes de organizaciones autónomas. Este fue el caso, para hablar de un ejemplo, del Consejo Popular Libertad en la Habana.

Este consejo estaba formado por varios barrios sin una gran identificación histórico-cultural, lo que motivó a sus líderes, especialmente a su presidenta, una mujer muy dinámica que había tomado varios seminarios sobre educación popular en una ONG cubana, a organizar diversos proyectos de participación entre los pobladores. De esta convocatoria brotaron proyectos tan disímiles como una asociación canina y un movimiento cultural por el rescate de una vivienda semiruinosa donde había vivido y trabajado el pintor cubano Wilfredo Lam. Al cabo del tiempo el consejo era una red de relaciones horizontales en función del desarrollo comu- nitario y con una perspectiva pluralista muy interesante que incluía perspectivas y roles diferenciados de los diferentes sectores sociales presentes en la comunidad en construcción.

Otro caso ha sido el del Consejo Popular de Santa Fe, al oeste de la ciudad de la Habana. Cuando comenzó la escasez de alimentos en 1990, varios pobladores de Santa Fe comenzaron a cultivar terrenos propios o estatales en desuso. El Estado no sólo les ofreció el usufructo de estos últimos, sino que envió a la localidad a un agrónomo para que les proveyera de asesoría técnica. El agrónomo resultó una persona interesada en técnicas de participación y en agricultura verde, de manera que la asesoría evolucionó hacia un proceso de organización comunitaria de horticultores (que dos años después llegaban a ser varios centenares) y de articulación de una agenda con fuerte acento ambientalista En este caso el consejo popular no fue el iniciador del proyecto, pero la protección política del consejo fue vital parea el despegue de la organización.

En otros casos, los movimientos comunitarios han tenido como escenarios iniciales la puesta en marcha de proyectos técnicos de remodelación barrial. Estos son los casos de los talleres de transformación integral de algunos barrios populares en la capital. En el más destacado de ellos, ubicado en el barrio de Atarés, un proyecto de construcción de viviendas y saneamiento ambiental fue paulatinamente derivando a un esquema de múltiples acciones en los campos de la atención a niños y adolescentes, acciones con madres solteras y mujeres agredidas, el rescate de las tradiciones culturales del barrio, etc.

También existen movimientos comunitarios originados en iniciativas municipales. En 1988 el municipio de Santa Clara prefirió concentrar todos sus recursos constructivos de viviendas en una circunscripción de un barrio insalubre -el Condado- ubicado en la periferia de la ciudad, para lo cual convocó a sus pobladores a organizarse. Lo hicieron con notable éxito, y generaron un liderazgo muy dinámico y heterogéneo que incluía a un activista cultural, a un médico comunitario y a la líder religiosa del barrio ${ }^{7}$.

Lo distintivo de estas nuevas experiencias comunitarias radica en tres puntos claves. En primer lugar, son proyectos que pretenden la transformación integral de los barrios desde diagnósticos propios (a diferencia de las organizaciones sociales y de masas tradicionales) y teniendo como ubicación principal a la sociedad civil emergente, lo que les distingue del trabajo municipal propiamente dicho. Para hacerlo pueden coincidir o no con estas otras organizaciones, y cuando lo hacen, logran una dinámica de interacción institucional altamente positiva. De aquí que son movimientos con un marcado sello local. Esto no implica que sus cosmovisiones estén reducidas al ámbito más estrecho de la comunidad. Son capaces de intercambiar experiencias

7. Esta enumeración es muy incompleta. Lamentablemente no existe un registro de las experiencias de organizaciones comunitarias en el país, ni de sus orígenes desde las casas culturales, los consejos populares, los municipios, etc. En una reciente reunión convocada por una ONG's cubana se dieron cita más de cuatro decenas de estas organizaciones, provenientes solamente de cinco de las 14 provincias del país. Para un examen interesante de algunas de estas experiencias puede consultarse (DÁvALOS y BASAIL, 1997). 
y metodologías, o alternar con las experiencias más universales, pero en todo momento cuidan su especificidad local como garantía de autenticidad.

En segundo lugar, son proyectos que sólo tienen asidero si logran una convocatoria participativa efectiva, y tratan de hacerlo tomando en cuenta la diversidad social y de motivaciones de las comunidades. De ahí que ensayan una suerte de pluralismo participativo inédito en la historia revolucionaria, al menos desde los 70. No quiero decir que siempre lo logran. Algunos de estos proyectos comunitarios no han podido convocar más que "élites" barriales influyentes, pero no decisivas, mientras que el resto de la población no rebasa un papel de consumidores de actividades básicamente lúdico culturales. Otros, como El Condado, han logrado una mayor participación en actividades como asambleas barriales para diagnósticos de salud y medio ambientales, pero según sus propios líderes, sus convocatorias nunca han podido ser atendidas por más del $40 \%$ de la población.

Por último, a diferencia de las organizaciones existentes, estatales o no, estos movimientos se caracterizan por la fluidez de sus liderazgos y de los vínculos horizontales. Aunque en algunos casos el origen estatal les ha marcado con un cierto sello "funcionarial" (lo que como veremos se acentúa cuando el Estado pretende una intervención mayor en sus asuntos) los liderazgos de estos movimientos tienen poco que ver con la forma de funcionamiento de las nomenclaturas oficiales. En sus "núcleos duros" aparecen figuras tan poco "ortodoxas" como activistas culturales, babalaos y ancianos, más allá de los cuales, los grupos de dirección tienden a inflarse o contraerse de acuerdo con las necesidades de cada momento. Y en ocasiones, estos líderes "informales" han pasado a ocupar posiciones de liderazgo "formal" al ser elegidos por la población como delegados del Poder Popular.

Una pregunta clave es en que medida estos movimientos y organizaciones comunitarias están provocando un cambio en la forma de pensar y en el ejercicio de la participación. Ciertamente lo están haciendo, e incrementando un acumulado cultural inexistente hace una década. Han logrado un impacto transformador importante en los barrios en que actúan, donde la vida y la autoestima de la gente es mejor ahora que cuando estas experiencias comenzaban. En ocasiones, han afectado positivamente a los mecanismos políticos formales. Pero nada de ello puede conducir a idealizaciones.

El desarrollo de los movimientos comunitarios está severamente afectado por el mismo centralismo y los mismos controles burocráticos que han impedido el despliegue del potencial participativo de los diseños formales. Cualesquiera de las experiencias comunitarias existentes, afronta una seria limitación de su autonomía por parte de una burocracia que no está habituada a compartir sus potestades con otros actores, excepto si ello le produce beneficios en función de la reproducción de su proyecto de poder. Mientras se trata de movimientos cuyas agendas son complementarias a la del Estado en términos casi puntuales -trabajos preventivos del delito, atención a grupos vulnerables, limpieza de calles, producción de alimentos para el consumo familiar, reanimación cultural, etc.- el Estado les protege y estimula, cultivando una suerte de versión aggiornada de las "correas de transmisión". A partir del momento en que estas organizaciones desbordan los límites asistenciales o lúdico culturales -ventas de excedentes de producción, conformación de cooperativas de productores, manejo de recursos propios o acceso a recursos externos- entran en conflicto con las autoridades estatales y son sometidas a un régimen disciplinario que les condena a una vida vegetativa y eventualmente a la extinción.

\section{IV. ¿DESDE DÓNDE ESTAMOS?, ¿ADÓNDE VAMOS?}

La sociedad cubana se encuentra en un momento crítico que sólo podrá resolverse a partir de redefiniciones medulares de sus formas de reproducción, sus relaciones de poder y sus expresiones públicas. La principal fuerza motriz de estas redefiniciones proviene del mercado mundial capitalista, al cual la economía cubana debe insertarse en condiciones particularmente difíciles. La voluntad de la clase política cubana de evitar el camino trillado por sus homólogas latinoamericanas -ajustes neoliberales en detrimento de los sectores populares- es un dato relevante y positivo, pero no suficiente para garantizar a la sociedad cubana un futuro diferente, mucho menos para conservar las conquistas populares de los últimos decenios. La dinámica cubana contemporánea conduce inevitablemente a la erosión de la alianza sociopolítica que dio vida a la Revolución, y a la traducción de sus principales postulados en nombre del realismo y del pragmatismo. $Y$ tras esa puerta hay un solo camino que conduce a la restauración del capitalismo tercermundista y dependiente, y a una frustración cultural comparable a la que sacudió a la sociedad cubana a inicios del siglo que termina.

No es, por supuesto, el único destino posible. La sociedad cubana no sólo ha estado expuesta a una alta calificación educacional, sino que también ha estado experimentado una fuerte socialización de valores solidarios y un fuerte apego al sentido de la justicia social. Ello constituye una matriz muy favorable para explorar vías que pueden conducir a una continuidad del proyecto de vocación socialista, o al menos a la expansión y consolidación de espacios de acción popular que sustenten la posibilidad real de una alternativa anticapitalista en el futuro. En otros artículos me he detenido en algunas de estas vías: expansión de la actividad cooperativa en la producción, la distribución y el consumo; establecimiento de zonas de cogestión y autogestión en la economía, reestructuración política en función de una mayor democratización, etc. (Dilla, 1995). Y por supuesto, en relación con esto último, una sociedad más participativa.

Sin embargo, poco de utilidad agregamos cuando afirmamos que Cuba debe ser una sociedad más participativa, o que debe avanzar en la construcción de una democracia participativa. Nadie diría lo opuesto, no importa desde cual trinchera ideológica. Más propositivo y polémico sería referirse al para qué se desea más participación y como lograrla. De alguna manera ya nos hemos referido al primer interrogante en el primer párrafo de este acápite: la participación es imprescindible para extender y consolidar los cotos de 
poder popular, enfrentarlos a la colonización mercantil de la vida cotidiana -que curiosamente marcha de la mano con el mantenimiento de una paz social imprescindible para la acumulación- y en esa medida, también para generar una cultura alternativa que herede y reproduzca el legado solidario y emancipatorio de la Revolución. En este contexto, las comunidades habitacionales y los municipios tienen un lugar muy especial.

Una primera condición para una participación efectiva en los términos antes descriptos, es la descentralización del poder político. Durante lustros la participación comunitaria ha convivido con una alta concentración de la autoridad que le redujo a un acto agregativo de demandas consumidas por un Estado con recursos abundantes y una alta sensibilidad social. Veamos la parte positiva: las poblaciones cubanas fueron dotadas de redes de servicios sociales y programas de desarrollo en función de la equidad territorial y social que resultan realmente envidiables. El costo ha sido la implantación de un esquema de subordinación del ciudadano común que hoy entra en contradicción con la alta calificación de ese mismo ciudadano. También una uniformidad de los diseños normativos y proceditivos que difícilmente puedan ser compatibles con la creciente diferenciación regional y social. Y de cualquier manera todo hace pensar que las virtudes mencionadas al principio no podrán mantenerse ante el nuevo código de la reproducción social.

Los espacios locales comienzan a remodelarse de acuerdo con la lógica del mercado, e incluso adaptados a las posibilidades de contacto con el mercado mundial capitalista; esta lógica sólo puede producir desigualdad y desarrollo discontinuo. Esto es observable en la transformación que sufren las regiones que han experimentado una vinculación más efectiva con las actividades económicas dinámicas. El establecimiento de zonas francas, la extensión del turismo y la descentralización empresarial deben producir impactos similares en otras regiones del país. Al mismo tiempo, ya es perceptible la existencia de zonas con un marcado empobrecimiento, particularmente en regiones que fueron tradicionalmente subsidiadas o que constituyeron polos de crecimiento industrial orientados al mercado soviético sin posibilidades de reconversión. La crisis azucarera y el probable desmantelamiento de buena parte de los ingenios es un ejemplo dramático.

En consecuencia, se produce un nuevo proceso de regionalización alineado con los imperativos del mercado mundial y cuya lógica solo podrá ser afectada parcialmente por un plan central. Un ejemplo visible de ello pudiera ser la franja costera de Ciudad de La Habana. Cualquier transeúnte puede apreciar el signo distintivo de la franja costera que empieza en el casco histórico colonial -La Habana Viejay se extiende hacia el oeste por más de una veintena de kilómetros. Allí se desarrollan la mayoría de los negocios emergentes: turismo, firmas descentralizadas, inversiones en bienes raíces, investigaciones y producciones apoyadas en tecnologías de punta, y otras actividades, formales o informales. Los espacios urbanos son remodelados por iniciativa estatal o privada, y comienzan a aparecer, junto a las cadenas criollas de comida rápida standarizada, zonas con negocios florecientes de restaurantes privados y alquileres de viviendas, que en algunos casos disponen de sistemas propios de iluminación "pública" y de guardianes privados. Es presumible que también en esta franja tienda a asentarse la población más activa profesional y económicamente. En cambio, otras zonas -el sur de la ciudad o los municipios periféricos- muestran una dinámica más rutinaria y pudieran estar destinados a albergar la población menos activa en el sentido apuntado: jubilados, obreros, etc.

Como antes señalaba, esta es una tendencia inevitable, pero no fatal. Existen numerosos medios públicos para afectar su trayectoria en función de un desarrollo equitativo y sostenible. No todos estos medios pertenecen al arsenal de la descentralización, sino al contrario: es necesaria una acción central que compense la creciente desigualdad con transferencias de recursos desde las áreas más favorecidas a las menos favorecidas. Pero también es posible creer que la existencia de gobiernos locales fuertes y con atribuciones para actuar de manera decisoria y coactiva en sus jurisdicciones sería imprescindible para la movilización óptima y un uso más racional de los recursos locales, así como para concertar acuerdos con municipios vecinos en el marco de la ley y de la integridad nacional. En cambio, un gobierno local débil sólo podría ser arrastrado por esta dinámica y terminar siendo una pieza más del juego en perjuicio de sus capacidades para representar los intereses ciudadanos y también en perjuicio de la capacidad estatal en su conjunto.

No se trata aquí, sin embargo, de cualquier tipo de descentralización. De hecho, ocurre una descentralización en función de las empresas y las áreas económicas insertadas en el mercado mundial y no me cabe duda que el sistema político-administrativo cubano experimentará grados mayores de descentralización en el futuro. El punto crucial es si esta descentralización irá en beneficio de las clases políticas y las burocracias locales, o si efectivamente se tratará de una descentralización-socialización del poder. Esto último implicaría fortalecer las capacidades deliberativas de las reuniones vecinales y de las organizaciones sociales (existentes o por existir) en temas como los programas de desarrollo, los presupuestos, las políticas medioambientales, los derechos ciudadanos, etc., así como reservar a éstas, potestades decisivas para la fiscalización de los procesos y la evaluación de los resultados, mediante el flujo de la información relevante y suficiente.

Una dinámica como ésta fortalecería inevitablemente los rasgos positivos del sistema electoral municipal (nominación libre de candidatos por las comunidades y elecciones secretas y directas sin recurrencia a campañas electorales individuales o a injerencias de otras organizaciones políticas) y otorgaría a los órganos representativos locales un papel acorde con el status de supremacía consagrado por la Constitución. Probablemente, la forma de constitución de la representación merece ser complementada con otras formas tributarias de representaciones de intereses que tome en cuenta la diversidad existente en las sociedades locales (cuentapropistas, mujeres, cooperativistas, jóvenes, trabajadores de empresas ubicadas en las localidades).

Un segundo elemento central en esta propuesta es pensar la participación inseparable de la autonomía de las colectividades y las personas para decidir como participar (o no 
participar), sobre qué temas hacerlo y qué acciones deberían emprender para dar solución a los problemas planteados. Ello implicaría inevitablemente poner sobre el tapete el problema de la sociedad civil.

La discusión sobre la sociedad civil en Cuba ha estado sesgada por diversas motivaciones ideológicas que van desde su percepción como espacio de subversión contrarrevolucionaria por parte del gobierno norteamericano hasta su codificación por el gobierno cubano como una "sociedad civil socialista" administrada y controlada burocráticamente. No nos detendremos en esta discusión que he analizado en otro lugar (Dilla, 1999b). Sólo se desea plantear que la construcción democrática cubana no podrá prescindir de la idea de una sociedad civil vigorosa y contradictoria en si misma. Desde la izquierda, la única alternativa posible es precisamente fortalecer los espacios de organización y participación popular en esa sociedad civil emergente. Ello no implica producir una desvinculación entre los espacios de participación existentes y el Estado (lo que sería negar una genuina conquista popular) sino rearticular esta relación en pos de la mutua democratización de la sociedad civil y del Estado. Y pensar que ningún diseño general, no importa cuan calificado técnicamente pueda ser, podrá sustituir la iniciativa de las personas y las comunidades acerca de cómo participar.

La autonomía de la participación lleva a un tercer y último punto en el que deseamos detenernos: el pluralismo. La idea del pluralismo político en Cuba es otro campo minado por todo tipo de presuposiciones ideológicas. Cuando se habla aquí de pluralismo nos referimos a un orden y una cultura políticos que reconozca la diversidad existente y de cuenta de ella en la arena pública ${ }^{8}$.

Un enfoque consecuentemente pluralista de la participación es una condición indispensable para los fines socialistas. Las sociedades locales, como antes decía, no son lo que eran hace dos décadas. Se han hecho más complejas. El prototipo del empleado estatal sigue predominando, pero comparte el mercado laboral con otras modalidades en expansión como cooperativistas, trabajadores por cuenta propia (legalizados o no), empleados del sector privado incipiente y desempleados. El propio empleado estatal es hoy una figura más compleja en dependencia de su ubicación en áreas dinámicas o en áreas tradicionales. Al mismo tiempo, la detención del intenso proceso de movilidad social conduce (entre otros factores) a la maduración de autoidentidades sectoriales (generacionales, genéricas, étnicas, regionales, etc.). En resumen, los gobiernos locales deben afrontar ahora una sociedad civil pletórica de sujetos y actores diversos, cuyas demandas también tienden a ser diversas. Y que originan ideologías diferentes (posicionales, históricas, políticas) que, aún cuando en la mejor perspectiva confluyan mayoritariamente hacia un consenso socialista, implicarán necesariamente un consenso negociado en un escenario policéntrico.
La diversidad acarrea inevitablemente contradicciones, disensos y conflictos. La participación autónoma y pluralista conduce y expresa estos conflictos. Son conflictos inevitables en torno a la apropiación de recursos limitados y del propio espacio social. Durante cuarenta años la sociedad cubana conoció formas muy particulares de solución e integración de estos conflictos que ya hoy dejan de existir. El reto para la sociedad cubana es establecer los mecanismos de negociación y concertación de intereses disímiles sobre la base de la participación efectiva y la representación de los diferentes grupos e intereses en un marco esencialmente integrativo. En este sentido, es muy probable que los gobiernos y los sistemas políticos locales puedan resultar un campo privilegiado de experimentación y de ingeniería política vital para la meta de una democracia participativa inseparable de cualquier formulación socialista.

\section{BIBLIOGRAFIA}

ANPP (1997): Valoración sobre el IV proceso de rendición de cuenta de los delegados a los electores. La Habana.

Bowman, M. y Hapton, W. (1993): Democracias locales. México: Fondo de Cultura Económica.

DÁvalos, R. Y BASAIL, A. (1997): Desarrollo urbano: proyectos y experiencias de trabajo. La Habana: Universidad de la Habana.

Dilla, Haroldo (1995): “¿Cuba: cual es la democracia deseable?”. En Dilla, H (comp.) La democracia en Cuba y el diferendo con los Estados Unidos. La Habana: CEA

- (1996): "Comunidad, participación y socialismo: reinterpretando el dilema cubano". En Dilla, H (comp.): La participación en Cuba y los retos del futuro. La Habana: Centro de Estudios sobre América.

-(1999a): "Comrades and Investors: the Uncertain Transition in Cuba”. En Global Capitalism Versus democracy (Edit by Leo Panitch and C. Leys) Socialist Register 1999.

- (1999b): "The Virtues and Misfortunes of Civil Society". En NACLA, March-April.

Dilla, H. (et. al) (1993): Participación popular y desarrollo en los municipios cubanos. La Habana: Editora Política.

- Fernández, A. y CAstro, M. (1997): Movimientos barriales en Cuba: tres estudios de caso. El Salvador: FUNDE.

GarCíA, D. (1989): La organización estatal en Cuba. La Habana: Editorial de Ciencias Sociales.

Oxhorn, P. (1995): Organizing Civil Society. Penn: The Pennsylvannia University Press.

8. Esta enumeración es muy incompleta. Lamentablemente no existe un registro de las experiencias de organizaciones comunitarias en el país, ni de sus orígenes desde las casas culturales, los consejos populares, los municipios, etc. En una reciente reunión convocada por una ONG cubana se dieron cita más de cuatro decenas de estas organizaciones, provenientes solamente de cinco de las 14 provincias del país. Para un examen interesante de algunas de estas experiencias puede consultarse (DÁvALOS y BASAIL, 1997). 